\title{
Quercetin Modulates Aging Induced-Testicular Damage Via Increasing the Antioxidant Defense and the Immunolocalization of the Proliferating Cell Nuclear Antigen in Male Rats
}

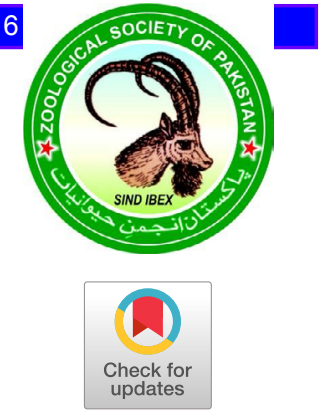

\author{
Eman A. Al-Shahari ${ }^{1,2}$, Abdelhalim A. Alkhazendar ${ }^{3}$, Eman R. ElBealy ${ }^{4}$ and \\ Abeer A. Alm-Eldeen ${ }^{3 *}$ \\ ${ }^{1}$ Department of Biology, Faculty of Science and Arts, King Khaled University, Abha, KSA \\ ${ }^{2}$ Department of Biology, Faculty of Science, Ibb University, Ibb, Yemen \\ ${ }^{3}$ Zoology Department, Faculty of Science, Tanta University, Tanta, Egypt \\ ${ }^{4}$ Biology Department, College of Science for Girls, King Khaled University, Abha, KSA
}

\begin{abstract}
A B S T R A C T
Aging is a natural process that affects testicular functions via increasing the oxidative stress. Quercetin, a polyphenolic, that has antioxidant activity. Therefore, this study was performed to examine the possible role of quercetin in modulating aging-induced testicular damage. Samples from 30-months old rats' testis were examined before and after $200 \mathrm{mg}$ of quercetin/ $\mathrm{Kg}$ administration. Before quercetin administration, they showed an increase in the lipid peroxidation and 8-hydroxy-2'-deoxyguanosine while showed a decrease in the superoxide dismutase activity, testosterone level and sperm count and viability. Seminiferous tubules diameters were $84.3 \pm 5.6 \mu \mathrm{m}$ and their epithelium heights were $21.2 \pm$ $3.4 \mu \mathrm{m}$. Only spermatogonia that were positively reacted with proliferating cell nuclear antigen (PCNA). After quercetin administration, they showed an improvement in the previous biochemical parameters. Seminiferous tubule diameters were $105.2 \pm 2.1 \mu \mathrm{m}$ and their epithelium heights were $26 \pm 2.1 \mu \mathrm{m}$. Remarkably, spermatogonia, spermatocytes, spermatids and sertoli were positively reacted with PCNA. In conclusion, quercetin could modulate aging induced-testicular damage via increasing the antioxidant defense and the immunolocalization of the proliferating cell nuclear antigen.
\end{abstract}

\begin{tabular}{l} 
Article Information \\
Received 12 October 2019 \\
Revised 01 December 2019 \\
Accepted 12 December 2019 \\
Available online 30 March 2021 \\
Authors' Contribution \\
\hline Alm-Eldeen conceived and designed \\
the study. Al-Shahari, Alkhazendar \\
and EIBealy collected and analysed the \\
data. Alkhazendar and Alm-Eldeen \\
wrote the manuscript. \\
Key words \\
\hline Testis, aging, oxidative stress, PCNA, \\
Quercetin
\end{tabular}

\section{INTRODUCTION}

$\mathrm{A}$ ging is a natural complex process which includes several irreversible changes that affect the biological functions. It is also characterized by morphological and structural deteriorations in many organs; one of these organs is the testis (Mao et al., 2019). Reactive oxygen and nitrogen species (ROS and RNS) that are produced by all aerobic cells play an important role not only in aging but also in age-related diseases (Venkataraman et al., 2013). The increase of ROS and RNS levels leads to the inhibition of the cellular proliferation in response to damages during replication (Liguori et al., 2018).

Several previous studies documented the deterioration in the testicular functions and structure with aging. Aging caused irreversible changes in the testis structures especially Leydig cells' numbers, the responsible cells for testosterone

\footnotetext{
* Corresponding author: abeer.eldeen@science.tanta. edu.eg; abeer75875@hotmail.com 0030-9923/2021/0003-1081 \$ 9.00/0

Copyright 2021 Zoological Society of Pakistan
}

hormone production (Tenover, 1998). An increase in the testicular metabolism was recorded from 11 to 40 years of age followed by its decrease from 40 to 90 years of age (Zenzmaier et al., 2008). A decline in the number of germ cells and Sertoli cells were recorded in aged individuals (Zitzmann, 2013). Furthermore, deteriorating changes were documented in the testosterone hormone production, spermatogenesis process and testes' mass with aging (Jenkins et al., 2015).

Proliferating cell nuclear antigen (PCNA) is a nuclear antigen known as $36-\mathrm{kDa}$ auxiliary nuclear protein for DNA polymerase delta. PCNA has an essential role not only in regulating DNA synthesis but also in the proliferation of the cells (Takasaki et al., 1981). Decrease in the number of the germ cells immunostained with PCNA in the testis reflects reduction in the proliferation activity and the spermatogenesis (Anbarkeh et al., 2019). Generally, aged animals had less numbers of basal germ cells in the seminiferous tubuli (Salama et al., 1998).

Quercetin, a flavonoid, is a polyphenolic natural chemical that has many biological activities such as antioxidant, cardioprotective, and neuroprotective 
(Vinayagam and $\mathrm{Xu}, 2015$ ). It can scavenge ROS due to its high content of the phenolic hydroxyl groups (Tokyol et al., 2006). It can inhibit the decline of steroidogenesis that is caused by the oxidative stress in aged Leydig cells (Chen et al., 2015). Moreover, via increasing the testosterone level, it enhanced the viability and the motility of the sperm in the diabetic rats (Khaki et al., 2010). It also could protect the testis from the toxicity induced by $\mathrm{CdCl}_{2}$ by its antioxidant activity (Nna et al., 2017). However, it is not clear yet if it can be used as a modulator against testicular deteriorations that is induced by the oxidative stress during aging. Therefore, the present study was undertaken to test the possible role of quercetin, as an antioxidant, to modulate the deteriorating testicular changes induced by aging in male rats.

\section{MATERIALS AND METHODS}

\section{Experimental protocol}

During experimental work guidelines of the Ethical Committee of King Khaled University, KSA were followed. Briefly, forty male albino rats of two different ages (3 and 30 months old) were used in the present study and were provided with a pellet diet that contains the essential nutritive elements. The rats were housed in plastic cages and maintained under standard conditions of temperature, humidity, and $12 \mathrm{~h}$ light/dark cycle for two weeks before starting the experiment. The rats were equally divided into 4 groups each of 10; group (1) rats, 3 months old were injected intraperitoneally (i.p.) with saline, (2) 3 months old rats and were injected i.p. with $200 \mathrm{mg}$ quercetin/Kg body weight, (3) 30 months old rats were injected i.p. with salaine and (4) 30 months old rats were injected i.p. with $200 \mathrm{mg}$ quercetin $/ \mathrm{Kg}$ body weight. The quercetin purchased from Sigma-Aldrich (St. Louis Mo., U.S.A) were injected every other day for 2 weeks (Alm-Eldeen et al., 2019). At the end of the experiment, the rats were sacrificed and the testes were carefully taken out under strict hygienic conditions. The right testes (10/ group) were stored in $-80{ }^{\circ} \mathrm{C}$ freezer for biochemical analyses and the left ones (10/group) were fixed in $10 \%$ neutral buffered formalin for histopathological and immunohistochemical examinations. Pieces from the epididymis were chopped for sperm count and viability.

\section{Determination of the testicular oxidative stress status}

Testes were homogenized in cold phosphate buffered saline centrifuged at $3000 \mathrm{xg}$ for $15 \mathrm{~min}$ at $4{ }^{\circ} \mathrm{C}$ to get supernatant for determination of superoxide dismutase (SOD) activity expressed as $\mathrm{U} / \mathrm{mg}$ protein according to Buege and Aust (1978) and lipid peroxidation (MDA) content expressed as nmole/mg protein according to Paoletti and Mocali (1990).
Quantification of 8-hydroxy-2'-deoxyguanosine (8-OHdG) Using enzyme-linked immunosorbent assay (ELISA) kit, the level of $8-\mathrm{OHdG}$ in the testis was determined according to the instructions of the manufacturer (Elabscience Biotechnology, China). The testes were homogenized in ice-cold saline, centrifuged at 1200xg for $15 \mathrm{~min}$ at $4{ }^{\circ} \mathrm{C}$ and the supernatant was collected. In each well, $50 \mu \mathrm{L}$ of standard or sample and $50 \mu \mathrm{L}$ of biotinylated antibody were incubated at $37^{\circ} \mathrm{C}$ for $45 \mathrm{~min}$, washed and then followed by adding $100 \mu \mathrm{L}$ of HRP conjugate and 90 $\mu \mathrm{L}$ of substrate reagent followed by adding $50 \mu \mathrm{L}$ of stop solution. The plates were then incubated at $37^{\circ} \mathrm{C}$ for 15 min and the absorbance was measured.

\section{Quantification of the testosterone}

Frozen testes were homogenated in RIPA lysis buffer at a concentration equal to $10 \mu \mathrm{l} / \mathrm{mg}$ of tissue then centrifuged at $12000 \mathrm{xg}$ for $10 \mathrm{~min}$. Using the ELISA assay kit (BOSTER Biological Technology Co., Ltd.), the levels of the testosterone was measured according to the instructions of the manufacturer. In each well, $50 \mu \mathrm{l}$ of the sample and $50 \mu \mathrm{l}$ of an enzyme-labeled antigen and $50 \mu \mathrm{l}$ of antibodies were added and incubated at $37^{\circ} \mathrm{C}$ for $45 \mathrm{~min}$. After 3 times washing, $50 \mu \mathrm{L}$ of substrate A (color developing agent) and $50 \mu \mathrm{L}$ of substrate B (color developing agent) were added to each well. The plates were incubated at $37^{\circ} \mathrm{C}$ for $15 \mathrm{~min}$ followed by the addition of $50 \mu \mathrm{L}$ of stop solution to each well then the absorbance was immediately measured.

\section{Sperm count and viability}

Pieces from the epididymis were cut in $5 \mathrm{ml}$ saline then incubated at $37^{\circ} \mathrm{C}$ for $15 \mathrm{~min} .5 \mu \mathrm{l}$ of the sperm suspension was diluted with $250 \mu \mathrm{l}$ of saline then $10 \mu \mathrm{l}$ was loaded to each counting chambers in the hemocytometer. Using light microscope at $400 \mathrm{X}$ magnification, the cells were counted then the sperm count was expressed as the number of spermatozoa/ ml (Zahra et al., 2013).

To determine the viability of the sperm, $5 \mu$ of $0.5 \%$ eosin was added to $10 \mu \mathrm{l}$ from the previous sperm suspension then incubated at room temperature for 2 min then loaded on a glass slide and viewed at $400 \mathrm{X}$ magnification. Live spermatozoa appeared white in color while dead ones appeared red to a pink in color. The sperm viability was calculated as the percentage of the live spermatozoa / 300 spermatozoa in each group.

\section{Histopathological and immunohistochemicl examination}

Formalin fixed testes were washed, dehydrated and embedded in paraffin. $5 \mu \mathrm{m}$ thick sections were cut. Some sections were processed for hematoxylin and eosin staining (Bancroft et al., 1994). Others sections were processed 
or for immunohistochemical staining from histological sections 100 random seminiferous tubules from each group using the objective lens X40 were analyzed to measure the diameter and the epithelium height of the seminiferous tubules.

\section{Immunohistochemicl examinations}

Sections were immunohistochemically stained with anti-PCNA using modified standard streptavidin-biotinperoxidase complex (ABC) method (Abou-Zaid et al., 2010). The sections were deparaffinized, hydrated, washed 3 times with phosphate buffered saline (PBS) then incubated with $3 \%$ hydrogen peroxide in methyl alcohol to block the peroxidase activity. The sections were then incubated with anti-PCNA biotin-conjugated antibody overnight at $4{ }^{\circ} \mathrm{C}$ then washed 3 times in PBS. PBS was added to some testis slides of 3 months old rats instead of PCNA to use them as a negative control. All sections were then incubated with biotinylated rabbit anti-polyvalent as a secondary antibody for $2 \mathrm{~h}$ at room temperature then washed 4 times in PBS. The sections were then incubated with Avidin, Biotin Complex (ABC) for $10 \mathrm{~min}$ at room temperature, and rinsed 3 times in PBS. To visualize the reaction, the slides were incubated with 3,3'-diaminobenzidine (DAB) for $10 \mathrm{~min}$ at dark then rinsed in PBS three times for $2 \mathrm{~min}$ each then counterstained with Mayers hematoxylin, rinsed in running tap water for $10 \mathrm{~min}$, dehydrated, cleared and mounted. The positive stained area was brown in color.

\section{Statistical analysis}

Four replicates from different animals in each parameter in all groups were taken and expressed as mean \pm standard deviation (mean $\pm \mathrm{SD}$ ). Two-way analysis of variance (ANOVA) was performed, then Tukey post hoc test was applied. P values $\leq 0.05$ was considered to be statistically significant. Statistical analysis was performed using Excel 2013 (Microsoft Corporation, USA), SPSS statistical version 22 software package (SPSS Inc., USA) and Minitab version 18).

\section{RESULTS}

\section{Effect of quercetin on SOD and MDA}

The data showed a non-significant difference $(\mathrm{p} \geq 0.05)$ in the testis SOD and MDA levels between the rats that had 3 months old before and after quercetin administration. The levels of the SOD were $27.96 \pm 1.37$ and $27.80 \pm 1.87$ and the levels of the MDA were $1.97 \pm 0.13$ and $2.03 \pm 0.14$ in the rats that had 3 months old before and after quercetin administration. The level of the testis SOD of the 30 months old rats showed a significant reduction $(\mathrm{p} \leq 0.05)$ while MDA level showed a significant increase $(\mathrm{p} \leq 0.05)$ with a percent of change equal to $-23.83 \%$ and $40.97 \%$ comparing with the 3 months old rats, respectively. Remarkably, the 30 month old rats that had received quercetin showed a non-significant difference $(p \geq 0.05)$ in the SOD and MDA levels comparing with the 3 months old rats before quercetin administration (Fig. 1A, B).
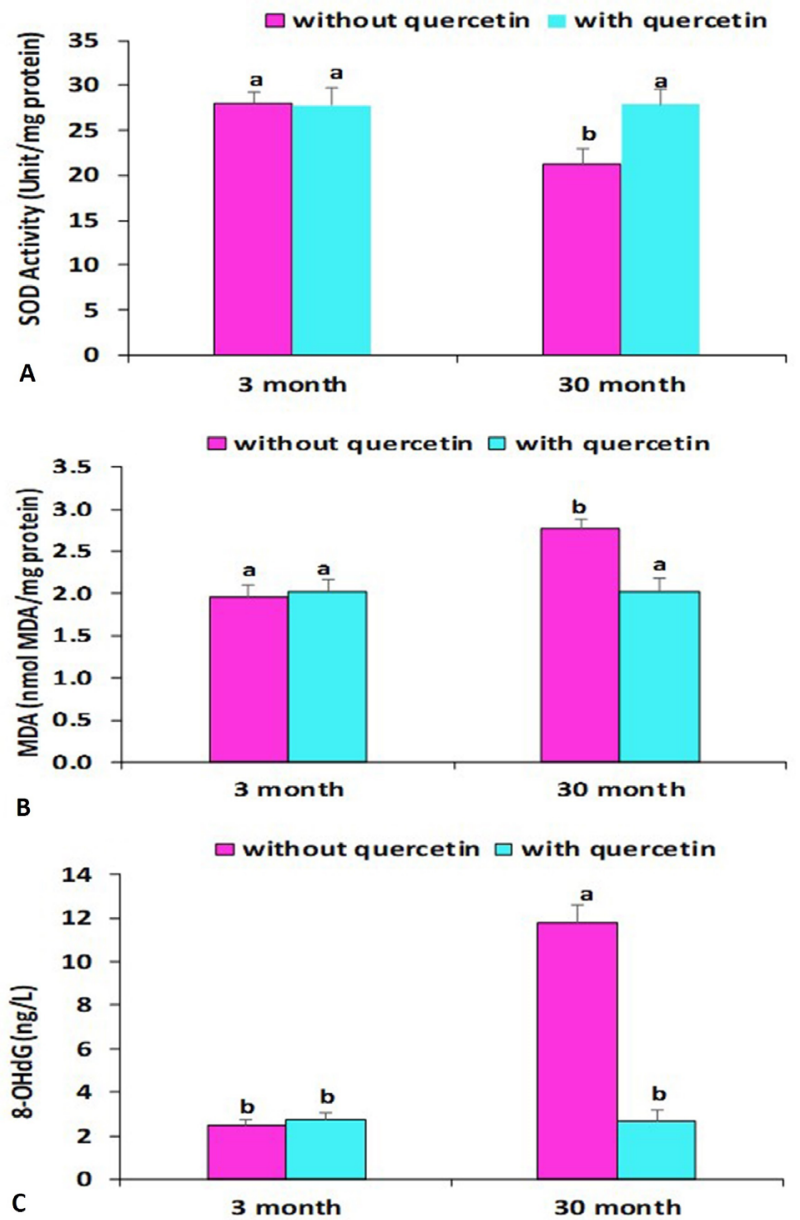

Fig. 1. Effect of quercetin on the levels of testes SOD (unit/ $\mathrm{mg}$ protein), MDA (nmol/ $\mathrm{mg}$ protein) and $8-\mathrm{OHdG}(\mathrm{ng} /$ L) in 3 and 30 months old rats before and after quercetin administration. Data are means \pm SD with $n=4$, Different letters indicate significant differences among the columns $(\mathrm{p} \leq 0.05)$.

\section{8-OHdG}

The results showed a non-significance difference $(p \geq 0.05)$ in the levels of $8-\mathrm{OHdG}$ in the rats that had 3 months old before and after quercetin administration. The levels of $8-\mathrm{OHdG}$ were $2.52 \pm 0.26 \mathrm{ng} / \mathrm{L}$ and $2.75 \pm 0.31$ $\mathrm{ng} / \mathrm{L}$, respectively. However, the rats that had 30 months old showed a significant increase $(\mathrm{p} \leq 0.05)$ in the level of $8-\mathrm{OHdG}$, which reached to $11.76 \pm 0.84 \mathrm{ng} / \mathrm{L}$ with a 
percent of change equal to $366.67 \%$, comparing with the rats that had 3 months old before quercetin administration. The rats that had 30 months old and received quercetin showed a non-significant change $(\mathrm{p} \geq 0.05)$ in the level of $8-\mathrm{OHdG}$, with a percent of change equal to $5.75 \%$, comparing with its level in the rats that had 3 months old before quercetin administration (Fig. 1C).

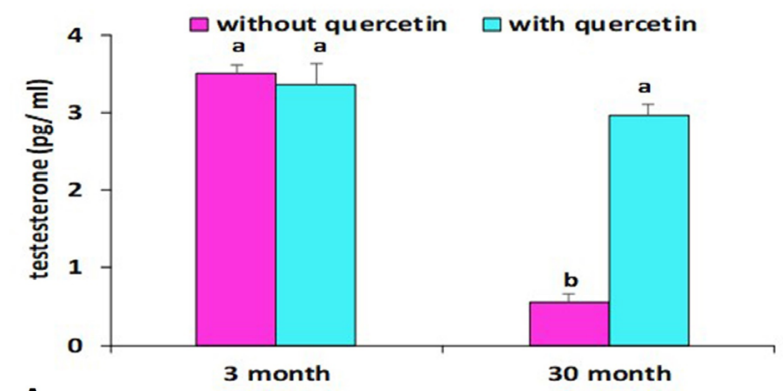

A

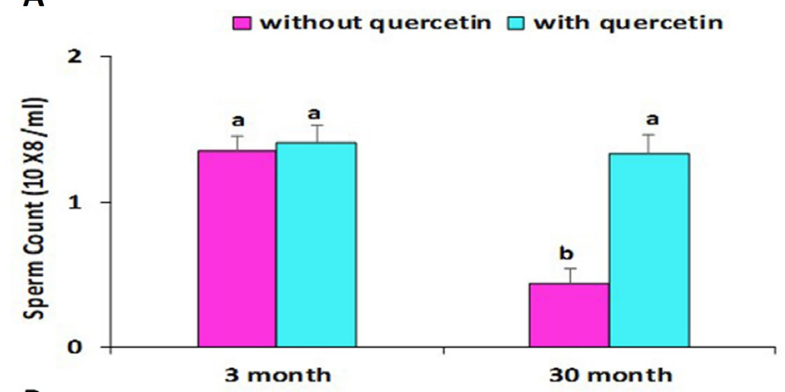

B

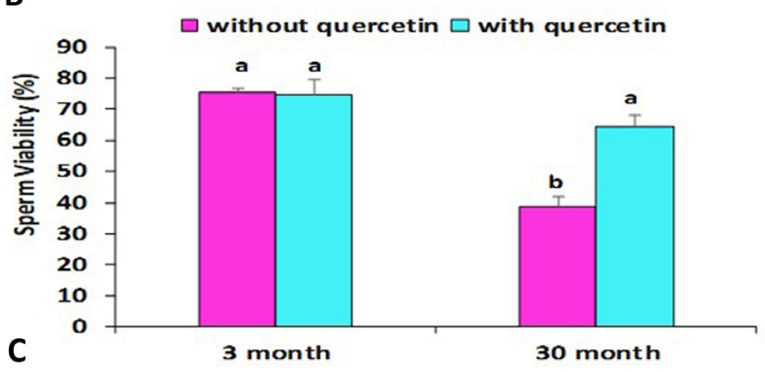

Fig. 2. Effect of quercetin on the testesterone $(\mathrm{pg} / \mathrm{ml})$, sperm count $(10 \mathrm{X} 8 / \mathrm{ml})$ and sperm viability (\%) in the 3 and 30 months old rats before and after quercetin administration. Data are means \pm SD with $n=4$, Different letters indicate significant differences among the columns $(\mathrm{p} \leq 0.05)$.

\section{Testosterone level}

The levels of the testosterone showed a non-significant difference $(p \geq 0.05)$ in the 3 months old rats before and after quercetin administration in which their levels were $3.52 \pm 0.10 \mathrm{pg} / \mathrm{ml}$ and $3.37 \pm 0.26 \mathrm{pg} / \mathrm{ml}$, respectively. However, the 30 months old rats showed a significant decrease $(\mathrm{p} \leq 0.05)$ in the testosterone level with a percent of change equal to $-84.01 \%$ compared with the 3 months old rats and not received quercetin. Interestingly, 30 months old rats injected with quercetin showed a non-significant change ( $\mathrm{p} \geq 0.05)$ with a percent of change equal to $-15.64 \%$ compared with the 3 months old rats that had not received quercetin (Fig. 2A).

\section{Sperm count and viability}

The data showed a non-significant change ( $p \geq$ 0.05 ) in the sperm count and viability in the 3 months old rats before and after quercetin administration. Sperm counts were $1.35 \pm 0.10 \times 10^{8}$ and $(1.40 \pm 0.12) \times 10^{8}$ and sperm viability was $75.58 \pm 1.31(\%)$ and $74.60 \pm 5.01$ $(\%)$ in the 3 months old rats before and after quercetin administration, respectively. However, these parameters showed a significant decrease $(\mathrm{p} \leq 0.05)$ in the 30 months old rats with a percent of change equal to $-67.35 \%$ and $-48.96 \%$ compared with the 3 months old rats that had not received quercetin, respectively. Remarkably, after quercetin administration, the 30 months old rats showed a non-significant change $(\mathrm{p} \geq 0.05)$ in the sperm count and viability with a percent of change equal to $1.33 \pm 0.13 \%$ and $64.58 \pm 3.53 \%$ compared with the 3 months old rats that had not received quercetin, respectively (Fig. 2B, C).

\section{Histological and immunohistochemical appearance}

Observation of the testis sections of the 3 months old rats before and after quercetin administration showing normal architecture. Seminiferous tubules appeared circular to oval in shape with normal seminiferous epithelium that contained all the stages of spermatogenesis from spermatogonia to mature sperm cells. Spermatozoa were clearly seen which filled the lumen. The diameter of the seminiferous tubule was $116.2 \pm 8.1 \mu \mathrm{m}$ and 111.6 $\pm 6.1 \mu \mathrm{m}$ while their epithelium height were $30.4 \pm 2.6$ $\mu \mathrm{m}$ and $28.4 \pm 2.1 \mu \mathrm{m}$ in the 3 months old rats before and after receiving quercetin, respectively (Fig. 3A, B). Moreover, spermatogonia, spermatocytes, spermatids and Sertoli were positively immunostained with PCNA. The pattern of PCNA reaction was quite similar in the 3 months old rats before and after quercetin administration. So, we decided to show the testis of 3 months old rat before the quercetin administration as a negative control, i.e. without PCNA exposure as a primary antibody (Fig. 4A, B). Observation of the testicular sections of the 30 month old rats revealed a significant $(p \leq 0.05)$ reduction in the diameter of the seminiferous tubules and the height of the seminiferous tubule epithelium. They reached to $84.3 \pm 5.6$ $\mu \mathrm{m}$ and $21.2 \pm 3.4 \mu \mathrm{m}$, respectively. Noticeable depletion of spermatogenic cells, round spermatids and sperms was recorded. As a result, the tubular lumen appeared much wider than in 3 month old rats (Fig. 3C). Moreover, positive PCNA reaction was noticed only in spermatogonia. 
Spermatocytes, spermatids and sertoli showed a negative reaction with PCNA (Fig. 4C). Interestingly, the 30 month old rats that had received quercetin showed nearly a normal histological structure of testis. Moreover, a nonsignificant $(\mathrm{p} \leq 0.05)$ difference in the diameter of the seminiferous tubules and the height of the seminiferous tubule epithelium were determined compared with the 3 month old rats before quercetin administration (Fig. 3D). The diameter of the seminiferous tubule reached 105.2 \pm 2.1 $\mu \mathrm{m}$ while their height were $26 \pm 2.1 \mu \mathrm{m}$. Spermatogonia, spermatocytes, spermatids and Sertoli were randomly positively immunostained with PCNA (Fig. 4D).
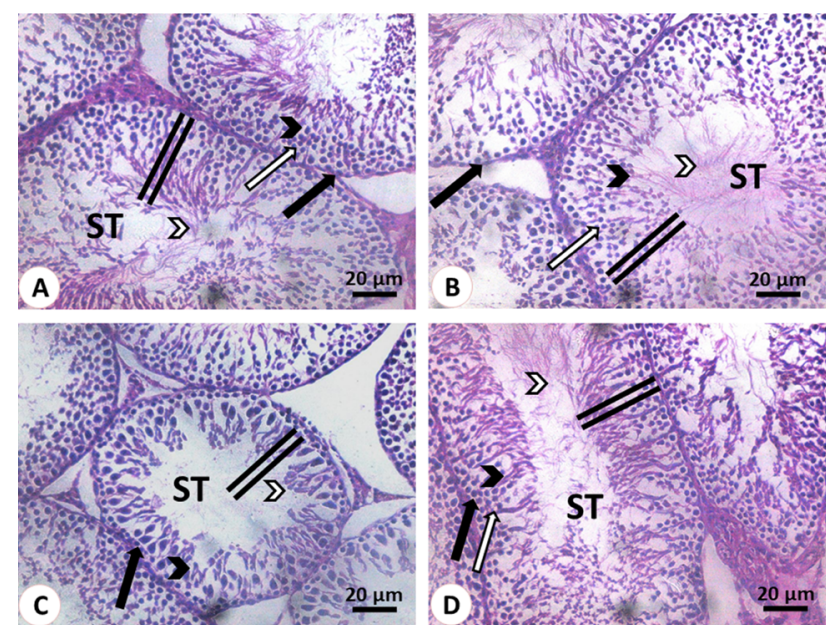

Fig. 3. Histological structure of the testis stained with hematoxylin and eosin. (A, B): 3 months old rats before and after quercetin administration, respectively. The seminiferous tubules (ST) showed normal seminiferous epithelium (double line) that contains spermatogonia (black arrow), spermatocytes (white arrow), spermatids (black arrowhead) and mature sperm (white arrowhead). (C, D): The seminiferous tubules (ST) of 30 months old rats before quercetin administration in $\mathrm{C}$ showed the depletion of spermatogenic cells (black arrow), round spermatids (black arrowhead) and sperms (white arrowhead). Note the reduction in the seminiferous tubules diameter and its epithelium height (double line). The seminiferous tubules (ST) of 30 months old rats after quercetin administration in D restore the normal structure. Note the height of its epithelium (line), spermatogonia (black arrow), spermatocytes (white arrow), spermatids (black arrowhead) and mature sperm (white arrowhead).

\section{DISCUSSION}

Continuous decline in the cellular function and body health are the most characteristic features of the aging process (Kong et al., 2014). Testicular dysfunction is a process that goes parallel to aging. Therefore, the present study was designed to clarify the possible role of quercetin, as antioxidant agent, to modulate the testicular damage induced by aging in male rats. The present data revealed decrease $-23.83 \%,-84.01 \%,-67.35 \%$ and $-48.96 \%$ in SOD, testosterone and the sperm count and viability $40.97 \%$ and $366.67 \%$ increase in MDA and 8-OHdG levels in 30 months old rats compared in the 3 months old rats. The present data were consistent with several previous studies that indicated the deterioration of the structure and functions of male reproductive organs with the progress of age (Wang et al., 2018). They recorded a decline in the testicular weight, testicular morphology, semen parameters and sperms viability and count with aging. Age causes an increase in the oxidative stress in the reproductive system (Aitken et al., 1989). This oxidative stress causes a decrease in the fertility represented by sperm production of less quality and numbers. The free radical theory suggested that aging is the cumulative result of oxidative damage to the cells and tissues that arises as a result of aerobic metabolism (Wickens, 2001). A relation was documented between the imbalance between the production and the degradation of ROS and aging (Liguori et al., 1918). ROS has the ability of oxidizing different types of proteins resulting into the
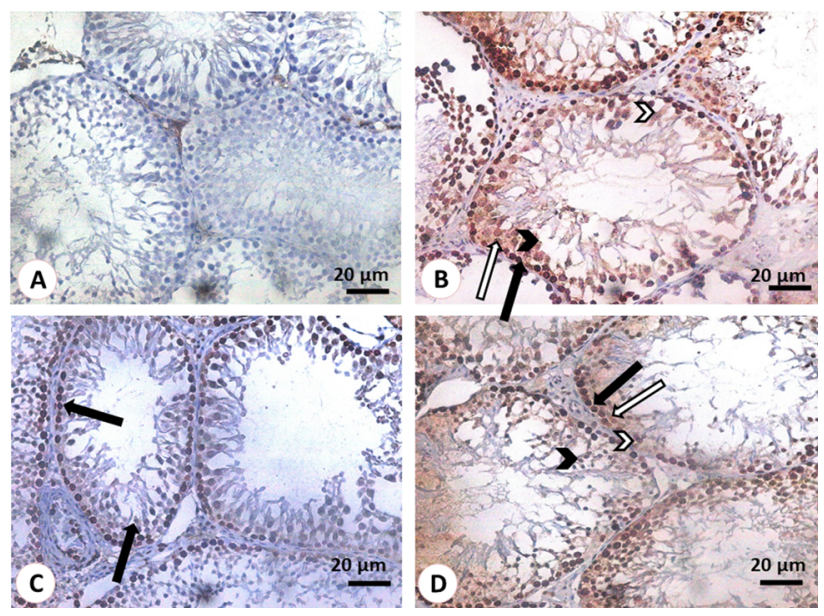

Fig. 4. Histological structure of the testis stained PCNA. $(\mathrm{A}, \mathrm{B}): 3$ months old rats before and after quercetin administration, respectively. In $A$, no reaction was observed was used as as we omitted PCNA antibody from the reaction and used it as a negative control. In B, Spermatogonia (black arrow), spermatocytes (white arrow), spermatids (black arrowhead) and Sertoli (white arrowhead) were positively immunostained with PCNA. (C, D): 30 months old rats before and after quercetin administration, respectively. In $\mathrm{C}$, only spermatogonia (black arrow) were positively immunostained with PCNA. In $\mathrm{D}$, spermatogonia (black arrow), spermatocytes (white arrow), spermatids (black arrow head) and Sertoli (white arrowhead) were positively immunostained with PCNA. 
damage of their structure and functions (Tousson et al., 2011; Alm-Eldeen et al., 2017). ROS plays one of the key roles in the occurrence of testis toxicity (Dirican et al., 2012). The decrease of the testis SOD and the increase of the testis MDA were recorded with aging due to the occurrence of the oxidative stress (Zhao et al., 2017). Furthermore, several studies reported an age-related increase in 8-OHdG levels in sperm (Paul et al., 2011; Ozkosem et al., 2015). High correlation has been reported between the oxidative adduct 8-OHdG and DNA fragmentation (Aitken et al., 2010). Spermiogenesis is exposed to errors with aging and sperm DNA was damaged because of its exposure to the oxidative attack that causes the increase in $8-\mathrm{OHdG}$ enzyme (Valavanidis et al., 2009).

The reduction of sperm count and viability which was in detected in 30 months old rats in the present study was in consonance with other previous studies that recorded a reduction in the seminal volume, percentage of motile sperm and percentage of morphologically normal sperm with aging (Johnson et al., 2015; Koh et al., 2016).

The histopathological examinations of the testicular tissues of 30 months old rats showed a decrease in the diameter of the seminiferous tubules and the height of their epithelium. PCNA which is a useful marker of cell proliferation was expressed only in spermatogonia. A decrease in the number of PCNA-positive cells with aging was already reported before (Uygur et al., 2016). The present reduction in PCNA expression in the testicular germ cells in 30 months old rats in the present study is an indication of a reduction in spermatogenesis and proliferative activities with aging.

Interestingly, 30 months old rats that received quercetin showed a non-significant difference in the SOD, MDA, OHdG, testosterone and the sperm count and viability compared with the 3 month old rats. Moreover, PCNA was expressed in spermatogonia, spermatocytes, spermatids and Sertoli. It was reported that quercetin, as antioxidant gent, has the ability to modulate the reduction of the SOD activities and the increase of the MDA levels associated with the increase in the oxidative stress in the testicular tissue (Uygur et al., 2014). The ability of quercetin to ameliorate the defects in the sperm quality and to increase the levels of testosterone in cadmium treated rats has also been reported by others (Farombi et al., 2012).

Quercetin could reduce the testicular damage induced by ethanol (Uygur et al., 2014), increase PCNA expression in testes of diabetic rats (Kanter et al., 2012), Repair testicular injury caused by cadmium injection during spermatogenesis (Farombi et al., 2012) and alleviate the atrazine-induced reduction in steroidogenic enzyme activities (Abarikwu and Farombi, 2016). This may be due to the protective effect of quercetin on testicular steroidogenesis and spermatogenesis due to its free radical scavenging properties (Abarikwu et al., 2013). Quercetin is considered more powerful antioxidant compared to other antioxidants such as vitamin $\mathrm{C}$, vitamin $\mathrm{E}$ and $\beta$-carotene (Rice-Evans et al., 1995). Quercetin, a flavonoid, has an antioxidant activity due to its higher diffusion into membranes (Moridani et al., 2003). Therefore, the improvement of the testicular morphology and function that had seen in 30 months old rats after quercetin administration in the preset study may be related to its antioxidant properties.

\section{CONCLUSION}

In conclusion, aging caused oxidative stress, lipid peroxidation and histopathological damage to testis. Quercetin could modulate aging induced-testicular damage via increasing the antioxidant defense and the immunolocalization of the proliferating cell nuclear antigen.

\section{ACKNOWLEDGEMENT}

The authors extend their appreciation to the Deanship of Scientific Research at King Khaled University for funding this work through general project under grant number (G.R.P. 245/1440).

\section{Conflict of interest}

No conflict of interest associated with this work.

\section{REFERENCES}

Abarikwu, S.O., Pant. A.B. and Farombi, E.O., 2013. Quercetin decreases steroidogenic enzyme activity, NF-jB expression and oxidative stress in cultured Leydig cells exposed to atrazine. Mol. Cell Biochem., 373: 19-28. https://doi.org/10.1007/ s11010-012-1471-z

Abarikwu, S.O. and Farombi, E.O., 2016. Quercetin ameliorates atrazine-induced changes in the testicular function of rats. Toxicol. Ind. Hlth., 32: 1278-1285. https://doi.org/10.1177/0748233714555389

Abou-Zaid, F.A., Salem, S.B., Madkour, G.A. and Alm-Eldeen, A.A., 2010. Histological and immunohistochemical studies on the pigeon endocrine pancreas at different ages. J. exp. Biol., 6: 385-394.

Aitken, R.J., Clarkson, J.S. and Fishel, S., 1989. Generation of reactive oxygen species, lipid peroxidation, and human sperm function. Biol. Reprod., 41: 183-197. https://doi.org/10.1095/ 
biolreprod41.1.183

Aitken, R.J., De Iuliis, G.N. and Finnie, J.M., 2010. Analysis of the relationships between oxidative stress, DNA damage and sperm vitality in a patient population: development of diagnostic criteria. Hum. Reprod., 25: 2415-2426. https://doi. org/10.1093/humrep/deq214

Alm-Eldeen A.A., Basyony M.A., Elfiky N.K. and Ghalwash M.M., 2017. Effect of the Egyptian propolis on the hepatic antioxidant defense and pro-apoptotic p53 and anti-apoptotic bcl2 expressions in aflatoxin B1 treated male mice. Biomed. Pharmacother, 87: 247-255. https://doi. org/10.1016/j.biopha.2016.12.084

Alm-Eldeen A.A., khamis A., Elfiky N.K. and Ahmad R.A., 2019. Quercetin modulates age-induced changes in the transcript levels of some apoptosis related genes in the skeletal muscles of male rats. Braz. J. Pharm. Sci., [Epub ahead of print].

Anbarkeh, F.R., Nikravesh, M.R., Jalali, M., Sadeghnia, H.R. and Sargazi, Z., 2019. The effect of Diazinon on cell proliferation and apoptosis in testicular tissue of rats and the protective effect of vitamin $\mathrm{E}$. Int. J. Fertil. Steril., 13: 154-160.

Bancroft, J.D., Cook, H.C. and Stirling, R.W., 1994. Manual of histological techniques and their diagnostic application. Churchill Livingstone, New York. pp. 457-458.

Buege, J.A. and Aust, S.D., 1978. Microsomal lipid peroxidation. Methods Enzymol., 52: 302-310. https://doi.org/10.1016/S0076-6879(78)52032-6

Chen, H., Guo, J., Ge, R., Lian, Q., Papadopoulos, V. and Zirkin, B.R., 2015. Steroidogenic fate of the Leydig cells that repopulate the testes of young and aged Brown Norway rats after elimination of the preexisting leydig cells. Exp. Gerontol., 72: 8-15. https://doi.org/10.1016/j.exger.2015.08.014

Dirican, E.K. and Kalender Y., 2012. Dichlorvos-induced testicular toxicity in male rats and the protective role of vitamin C and E. Exp. Toxicol. Pathol., 64: 820-830. https://doi.org/10.1016/j.etp.2011.03.002

Koh, S., Sanders K. and Burton, P., 2016. Effect of male age on oxidative stress markers in human semen. J. Reprod. Biotechnol. Fertil., 5: 1-10. https://doi. org/10.1177/2058915816673242

Farombi, E.O., Adedara, I.A., Akinrinde, S.A., Ojo, O.O. and Eboh, A.S., 2012. Protective effects of kolaviron and quercetin on cadmium-induced testicular damage and endocrine pathology in rats. Andrologia, 44: 273-284. https://doi.org/10.1111/ j.1439-0272.2012.01279.x

Hu, X.T., Ding, C., Zhou, N. and Xu, C., 2015. Quercetin protects gastric epithelial cell from oxidative damage in vitro and in vivo. Eur. J. Pharmacol., 754: 115124. https://doi.org/10.1016/j.ejphar.2015.02.007

Jenkins, T.G., Aston, K.I. and Meyer, T., 2015. Carrell DT. The sperm epigenome, male aging, and potential effects on the embryo. Adv. exp. Med. Biol., 868: 81-93. https://doi.org/10.1007/978-3319-18881-2 4

Johnson, S.L., Dunleavy, J., Gemmell, N.J. and Nakagawa, S., 2015. Consistent age-dependent declines in human semen quality: A systematic review and meta-analysis. Age. Res. Rev., 19: 2233. https://doi.org/10.1016/j.arr.2014.10.007

Kanter, M., Aktas, C. and Erboga, M., 2012. Protective effects of quercetin against apoptosis and oxidative stress in streptozotocin-induced diabetic rattestis. $F d$. chem. Toxicol., 50: 719-725. https://doi.org/10.1016/j.fct.2011.11.051

Khaki, A., Fathiazad, F., Nouri, M., Khaki, A., Maleki, N.A., Khamnei, H.J. and Ahmadi, P., 2010. Beneficial effects of quercetin on sperm parameters in streptozotocin-induced diabetic male rats. Phytother. Res., 24: 1285-1291. https://doi. org/10.1002/ptr.3100

Kong, Y., Trabucco, S.E. and Zhang, H., 2014. Oxidative stress, mitochondrial dysfunction and the mitochondria theory of aging. Interdiscip. Top. Gerontol., 39: 86-107. https://doi. org/10.1159/000358901

Liguori, I., Russo, G., Curcio, F., Bulli, G., Aran, L., Della-Morte, D., Gargiulo, G., Testa, G., Cacciatore, F., Bonaduce, D. and Abete, P., 2018. Oxidative stress, aging, and diseases. Clin. Interv. Aging, 13: 757-772. https://doi.org/10.2147/CIA.S158513

Mao, C., Yuan, J.Q., Lv, Y.B., Gao, X., Yin, Z.X., Kraus, V.B., Luo, J.S., Chei, C.L., Matchar, D.B., Zeng, Y. and Shi, X.M., 2019. Associations between superoxide dismutase, malondialdehyde and allcause mortality in older adults: A community-based cohort study. BMC Geriatr., 19: 104-112. https:// doi.org/10.1186/s12877-019-1109-z

Moridani, M.Y., Pourahmad, J., Bui, H., Siraki, A. and O'Brien, P.J., 2003. Dietary flavonoid iron complexes as cytoprotective superoxide radical scavengers. Free Radic. Biol. Med., 34: 243- 253. https://doi.org/10.1016/S0891-5849(02)01241-8

Nna, V.U., Ujah, G.A., Mohamed, M., Etim, K.B., Igba, B.O., Augustine, E.R. and Osim, E.E., 2017. Cadmium chloride-induced testicular toxicity in male wistar rats; prophylactic effect of quercetin, and assessment of testicular recovery following cadmium chloride withdrawal. 
Biomed. Pharmacother, 94: 109-123. https://doi. org/10.1016/j.biopha.2017.07.087

Ozkosem, B., Feinstein, S.I., Fisher, A.B., 2015.Advancing age increases sperm chromatin damage and impairs fertility in peroxiredoxin 6 null mice. Redox Biol., 5: 15-23. https://doi.org/10.1016/j.redox.2015.02.004

Paoletti, F. and Mocali, A., 1990. Determination of superoxide dismutase activity by purely chemical system based on NAD(P)H oxidation. Methods Enzymol., 186: 209-220. https://doi. org/10.1016/0076-6879(90)86110-H

Paul, C., Nagano, M. and Robaire, B., 2011. Aging results in differential regulation of DNA repair pathways in pachytene spermatocytes in the brown Norway rat. Biol. Reprod., 85: 1269-1278. https://doi. org/10.1095/biolreprod.111.094219

Rice-Evans, C.A., Miller, N.J., Bolwell, P.G., Bramley, P.M. and Pridham, J.B., 1995. The relative antioxidant activities of plant-derived polyphenolic flavonoids. Free Radic. Res., 22: 375-383. https:// doi.org/10.3109/10715769509145649

Salama, H., Salama, M.A., Garber, D. and Adar, P., 1998. The interproximal height of bone: A guidepost to predictable aesthetic strategies and soft tissue contours in anterior tooth replacement. Pract. Period. Aesthet. Dent., 10: 1131-1141.

Takasaki, Y., Deng, J.S. and Tan, E.M., 1981. A nuclear antigen associated with cell proliferation and blast transformation. J. exp. Med., 154: 1899-1909. https://doi.org/10.1084/jem.154.6.1899

Tenover, J.L., 1998. Male hormone replacement therapy including 'andropause'. Endocrinol. Metab. Clin. N. Am., 27: 969 - 987. https://doi.org/10.1016/S08898529(05)70050-5

Tokyol, C., Yilmaz, S., Kahraman, A., Cakar, H. and Polat, C., 2006. The effects of desferrioxamine and quercetin on liver injury induced by hepatic ischaemia-reperfusion in rats. Acta Chir. Belg., 106: 68-72. https://doi.org/10.1080/00015458.2006.1167 9837

Tousson E., Alm-Eldeen A. and El-Moghazy M., 2011. p53 and $\mathrm{Bcl} 2$ expression in response to boldenone induced liver cells injury. Toxicol. Ind. Hlth., 27: 711718. https://doi.org/10.1177/0748233710395350

Uygur, R., Aktas, C., Caglar, V., Uygur, E., Erdogan, H. and Ozen, O.A., 2016. Protective effects of melatonin against arsenic-induced apoptosis and oxidative stress in rat testes. Toxicol. Ind. Hlth., 32: 848-859. https://doi.org/10.1177/0748233713512891

Uygur, R., Yagmurca, M., Alkoc, O.A., Genc, A., Songur, A., Ucok, K. and Ozen, O.A., 2014. Effects of quercetin and fish $\mathrm{n}-3$ fatty acids on testicular injury induced by ethanol in rats. Andrologia, 46: 356-369. https://doi.org/10.1111/and.12085

Valavanidis, A., Vlachogianni, T. and Fiotakis, C., 2009. 8-hydroxy-2'-deoxyguanosine (8-OHdG): a critical biomarker of oxidative stress and carcinogenesis. J. Environ. Sci. Hlth. Environ. Carcinog. Ecotoxicol. Rev., 27:120-139. https://doi. org/10.1080/10590500902885684

Venkataraman, K., Khurana, S. and Tai, T.C., 2013. Oxidative stress in aging--matters of the heart and mind. Int. J. mol. Sci., 14: 17897-17925. https://doi. org/10.3390/ijms 140917897

Vinayagam, R. and Xu, B., 2015. Antidiabetic properties of dietary flavonoids: A cellular mechanism review. Nutr. Metab., 23: 12-60. https://doi.org/10.1186/ s12986-015-0057-7

Wang, S., Hu, B., Ding, Z., Dang, Y., Wu, J., Li, D., Liu, X., Xiao, B., Zhang, W. and Ren, R., 2018. ATF6 safeguards organelle homeostasis and cellular aging in human mesenchymal stem cells. Cell Discov., 4: 1-19. https://doi.org/10.1038/s41421-017-0003-0

Wickens, A.P., 2001. Ageing and the free radical theory. Respir. Physiol., 128: 379-391. https://doi. org/10.1016/S0034-5687(01)00313-9

Zahra, A., Gholamreza, N., Farokhi, F. and Shalizar Jalali, A., 2013. Attenuation of cyclosporine-induced sperm impairment and embryotoxicity by Crataegus monogyna fruit aqueous extract. Cell J., 15: 198-205.

Zenzmaier, C., Untergasser, G. and Berger, P., 2008. Aging of the prostate epithelial stem/progenitor cell. Exp. Gerontol., 43: 981-985. https://doi.org/10.1016/j. exger.2008.06.008

Zhao, H., Song, L., Huang, W., Liu, J., Yuan, D., Wang, Y. and Zhang, C., 2017. Total flavonoids of Epimedium reduce ageing-related oxidative DNA damage in tests of rats via p53-dependent pathway. Andrologia, 49: e12756. https://doi.org/10.1111/and.12756

Zitzmann, M., 2013. Effects of age on male fertility. Best Pract. Res. Clin. Endocrinol. Metab., 27: 617-628. https://doi.org/10.1016/j.beem.2013.07.004 